\title{
Achievement of Statistical Reasoning Ability for Athletes and Nonathletes
}

\author{
Nidaul Hidayah* \\ Fakultas Pendidikan Olahraga dan Kesehatan \\ Universitas Pendidikan Indonesia \\ Bandung, Indonesia \\ *nidaul@upi.edu
}

\begin{abstract}
The purpose of this study is to describe the achievement of statistical reasoning ability (SRA) of sporting students who work as athletes and not athletes in learning Statistical Reasoning Learning Environment (SRLE). This study uses quantitative analysis with quasi-experimental methods. The research subjects consisted of sports students from the study program, namely the Sports Coach Education Study Program where 25 students who received SRLE learning were athletes and 4 non-athletes and direct learning students respectively 23 students who are athletes and 6 students who are not athletes. The conclusion obtained in this study is that there is a difference in the increase in SRA between professional category students (athletes, non-athletes) who get SRLE and direct learning.
\end{abstract}

Keywords: achievement of statistical reasoning ability, sports students, SRLE learning

\section{INTRODUCTION}

Statistics in the world of sports play an important role because there are many measurement results in sports that need to be processed and analysed through statistics. The results of processing and analysing this data are very useful in obtaining conclusions or decisions to improve the quality of physical education learning, develop training programs or choose the right measurement tools to improve achievement. The use of statistics in sports is unavoidable because in various competitions and competitions there will be achievements that are expressed with speed (in running and swimming), with frequency (number of scores entered), for example in basketball, soccer, badminton, volleyball and so on so that the results of the matches and competitions produce data that can be processed and presented statistically.

An example of the role of statistics in sports presented in sports statistics research is modelling the development of world records in running research by Kuper of the University of Groningen [1] illustrates a development of the world record model of a race run from 100 meters to marathon numbers for men and women with the times-series method and the "Statistical Analysis of the Effectiveness of the FIFA World Rankings" researched by Mchale from the University of Salford [2], where this study builds forecast models for the results of soccer matches between national team, and assess the extent to which the information included has been given an appropriate weighting in FIFA rankings, in Albert \& Koning's [3].

Statistical learning can be presented in various contexts. For example in the context of education, economics, health, agriculture as well as sports contexts. Reference in the book "Statistical Reasoning in Sport" provides an overview of how statistical learning is delivered with sports as its context [4]. In this study, match data, training results data and actual measurement results data are used for sports investigations obtained through various media both internet and directly from the field. According to Kvam statistical material can be very well illustrated using data and appropriate examples from sports and showing that most students enjoy sports examples (sports as contexts) in statistical learning with pleasure as a way to learn abstract concepts using familiar settings and a lot of fun [5]. Examples of popular sports in America such as baseball, basketball and soccer.

Statistical reasoning is defined as a way of reasoning involving statistical ideas and information [6-10]. For example: making interpretations based on data, data representation, or summary statistics from data. Statistical reasoning can be a combination of ideas and probabilities, such as inferring and interpreting statistical results. Statistical reasoning means understanding concepts and being able to explain statistical processes, and being able to fully interpret statistical results [11-14]. Then, Lovett interprets statistical reasoning as using statistical tools and statistical concepts to summarize, make predictions about data, and draw conclusions from data [15]. A similar statement was proposed by Garfield that statistical reasoning is a way of thinking using statistical information facts [16].

Thus statistical reasoning can be defined as a way of reasoning by involving statistical ideas and information to summarize, make predictions about the data and draw conclusions from the data. The ability of statistical reasoning is the ability to understand statistical concepts, explain the statistical process and interpret statistical results based on statistical ideas and information.

This statistical reasoning ability is very important for sports students because in sports student activities many things can be used as statistical learning materials in matches, test results and measurements, predicting achievements that can be achieved based on the training process, seeing the relationship between 
one variable with other variables. The researcher tried an instrument to measure the ability of statistical reasoning with regard to the introduction of data types, probabilities, reading tables, describing and explaining them with bar and pie charts, explaining variability, reading, calculating and explaining the mean, median and mode of trying 50 students of science studies sports so that the following results are obtained, from the overall students only $26 \%$ who have abilities above $30 \%$ while others below $30 \%$ while viewed from each material is the introduction of $56 \%$ data types, reading tables, illustrating, and explaining them with graphs is $49 \%$, probability $27 \%$, explain variability $33 \%$, read, calculate and explain the mean, median and mode $16.32 \%$. The results of the measurement trials above show that the statistical literacy and statistical reasoning abilities of sports students are inadequate, so increasing the statistical literacy and statistical reasoning abilities is very necessary for sports students.

The learning model that will be used in this study is a learning model to develop the statistical reasoning abilities introduced by Garfield, namely "Statistical Reasoning Learning Environment" or abbreviated SRLE [17]. SRLE is a learning model based on constructivist social theory with six learning principles designed by Cobb and McClain which focus on developing statistical content, using real data, using class activities, using technological assistance, improving classroom conversation and using alternative assessments [11].

Through the SRLE learning model it is expected to have a positive impact on the quality of statistical learning outcomes in sports students both athletes and non-athletes so as to improve statistical reasoning abilities that are very useful for sports people as athletes, teachers, coaches, sports scientists or other sports people. In this study aims to find a picture of increasing the ability of statistical reasoning of sports students based on the profession of athletes and non-athletes.

\section{Method Of RESEARCH}

This research was conducted for 8 (eight) months. The place of research was conducted in Sport Coaching Education (PKO) Department of Faculty of Sports and Health Education (FPOK), Indonesia University of Education. The method used in this research is the group pretest-posttest method. The research method used is experimental research which applied SRLE learning. The design in this research was 'quasiexperiment'. In this quasi-experiment, it uses two categories of sample classes namely experimental and control classes.

The objects of this research are statistical reasoning ability and SRLE and DL learning model. Then, the subject in this study is students of Sport Coaching Education Department of Faculty of Sports and Health Education in Indonesia University of Education who took statistics course. The data collection instrument used is the statistical reasoning ability test in the form of questions related to the introduction of reading the chart, describing, and explaining it with graphs, explaining variability, reading, calculating and explaining the mean, data presentation, relationship between variables, and hypothesis testing.

This research was conducted in three stages. First, pre-test that aim to know the ability of student reasoning before being given the treatment, then the sample is divided into two groups which are experimental group and control group. Second, treatment is in the form of learning with SRLE learning model (experiment group) and the direct learning model (DL) for the control group. Third, post-test that aim to know students statistical literacy after the treatment. The research was conducted in Short Semester lecturing (SP) with 58 students as sample. 29 (25 students as athletes and 4 non-athletes) students of them are placed in the experimental group and 29 (23 students as athletes and 6 non-complete students) of them are in the control group. In this research, the statistical material given is the inferential statistical material which is done in 10 times meeting.

\section{RESULTS AND DISCUSSION}

Data analysis of increasing statistical reasoning ability (SRA) was obtained from the results of $\mathrm{N}$-gain statistical reasoning ability which included average, standard deviation based on profession and learning for PKO study programs. Data recapitulation of increasing statistical reasoning ability (SRA) based on profession (athlete and non-athlete) is presented in Table 1 below:

TABLE I. THE KPS IMPROVEMENT SCORE DATA FOR STUDY PROGRAM STUDENTS ARE BASED ON PROFESSIONS From TwO LEARNING GROUPS

\begin{tabular}{|l|l|l|l|}
\hline Category & \multirow{2}{*}{ Statistic } & \multicolumn{2}{|c|}{ PKO } \\
\cline { 3 - 4 } & & \multicolumn{2}{|c|}{ Learning } \\
\cline { 3 - 4 } & & 25 & \multicolumn{2}{|c|}{ PRLE } \\
\hline \multirow{4}{*}{ Athlete } & $n$ & 0,49464908 & 0,21157622 \\
\cline { 2 - 4 } & $\bar{x}$ & 0,155101156 & 0,162474034 \\
\cline { 2 - 4 } & $s$ & 4 & 6 \\
\hline \multirow{2}{*}{$\begin{array}{l}\text { Athlete } \\
\end{array}$} & $n$ & 0,57962975 & 0,37992333 \\
\cline { 2 - 4 } & $\bar{x}$ & 0,222438237 & 0,312227329 \\
\cline { 2 - 4 } & $s$ & & \\
\hline
\end{tabular}

Based on Table 1, descriptively the average increase in SRA for students who received SRLE learning was higher than students who received PL learning based on the profession of athletes and non-athletes for PKO study programs. For SRLE learning and direct learning the average increase in non-athlete statistical reasoning ability is higher than the average increase in athlete statistical reasoning ability.

To find out the increase in the ability of statistical reasoning for athletes and non-athletes students from both learning groups, hypothesis testing will be conducted. However, before conducting the test, it is necessary to test the statistical assumptions namely the normality test for data from two groups of students. Normality test results show that the data obtained (N-gain) from the direct learning group and $\mathrm{N}$-gain from SRLE (experimental group) are normally distributed at $\alpha$ $=0.05$, this is indicated by the probability value of $\mathrm{sig}>0.05$.

$\mathrm{N}$-gain data from the statistical reasoning ability of the two study groups will be tested whether there are differences or not to strengthen the impact of the applied SRLE learning model. The average $\mathrm{N}$-gain test results from two sample groups between the experimental group (SRLE learning model) and the control group (direct learning model) for athletes using the 
t-test are as follows: The t-test results presented in Table 2 below:

TABLE II. THE INCREASE OF SRA MEAN RESUlt IN CONTROL AND EXPERIMENTAL GROUPS

\begin{tabular}{|l|l|c|c|c|}
\hline & t-value & Sig. & Ho & Interpretation \\
\hline N-gain & $-6,176$ & 0,000 & rejected & There difference \\
\hline
\end{tabular}

From Table 2, it is found that the value of $\mathrm{Sig}=0,000$ $<0.05$, which means that $\mathrm{H} 0$ is rejected and $\mathrm{H} 1$ is accepted. Because H1 was accepted, the hypothesis stating "There is a difference in the increase in SRA between PKO students' athletes who received SRLE learning and students who received PL learning" was accepted. This shows that there is a difference in the increase in SRA between PKO students' athletes who received SRLE learning and students who received PL learning. This was reinforced where descriptively the SRA grade average increase $(0.49464908)$ was higher than the PL grade SRA average increase (0.21157622), thus the average increase in PKO SRA students for athletes who learned SRLE is higher than students who get PL learning.

The average $\mathrm{N}$-gain test results from two sample groups between the experimental group (SRLE learning model) and the control group (direct learning model) for athletes using the t-test are as follows: The t test results for the non-athlete group obtained the results of the $t$ test presented in Table 3 as follows:

TABLE III. THE INCREASE OF SRA MEAN RESULT IN CONTROL AND EXPERIMENTAL GROUPS

\begin{tabular}{|l|c|c|c|c|}
\hline & t-value & Sig. & Ho & Interpretation \\
\hline N-gain & $-1,097$ & 0,304 & Not rejected & No difference \\
\hline
\end{tabular}

From Table 3, it was found that the value of Sig $=0.304>$ 0.05 , which means that $\mathrm{H} 0$ is accepted and $\mathrm{H} 1$ is rejected. Because H0 was accepted, the hypothesis stating "There is a difference in the increase in SRA between non-athlete students who received SRLE learning and students who received PL learning" was rejected. This shows that there is no difference in the increase in SRA between non-Athlete students who received SRLE learning and students who received PL learning. This means that on average the increase in SRA for non-Athlete students who received SRLE learning was no different from students who received PL learning.

The average $\mathrm{N}$-gain test results from two sample groups between the experimental group (SRLE learning model) and the control group (direct learning model) for athletes and nonathletes using the t-test are as follows: T-test results for the athletes and non-Athletes obtained t test results presented in Tables 4 as follows:
TABlE IV. T-Test: AVERAge DifFERENCE TEST Results For The INCREASE IN SRA FOR NON-ATHLETE STUDENTS WHO RECEIVED SRLE AND PL LEARNING

\begin{tabular}{|l|l|c|c|c|}
\hline & t-value & Sig. & Ho & Interpretation \\
\hline N-gain & $-1,285$ & 0,204 & Not rejected & No difference \\
\hline
\end{tabular}

From Table 4, it was found that the value of Sig $=0.204>$ $\alpha$, with $\alpha=0.05$, which means that $\mathrm{H} 0$ is accepted and $\mathrm{H} 1$ is rejected. Because H1 was rejected, the hypothesis stating "There is a difference in the increase in between Athlete and Non-Athlete PKO students who received SRLE and PL learning" was rejected. This shows that there is no difference in the increase in KPS between PKO Athletes and non-Athletes students who have SRLE and PL learning.

\section{CONCLUSION}

There is a difference in the increase in SRA between professional category students' athletes who get SRLE and direct learning. Not there is a difference in the increase in SRA between professional category students athletes and students non-athletes who get SRLE and direct learning. SRLE as a statistical learning alternative for sports students, both athletes and non-athletes

\section{ACKNOWLEDGMENT}

Thanks to Universitas Pendidikan Indonesia, special thanks to Fakultas Pendidikan Olahraga dan Kesehatan (FPOK).

\section{REFERENCES}

[1] Kuper and Sterken, "Modelling the development of world records in running," In Albert \& Koning, Statistical Thinking in Sports, Chapman \& Hall CRC, Taylor \& Francis Group, 2007.

[2] Mchale and Davies, "Statistical Analysis of the effectiveness of the FIFA World Rankings," in Albert \& Koning, Statistical Thinking in Sports, Chapman \& Hall CRC, Taylor \& Francis Group Maslow, 2007.

[3] J. Albert, K. Ruud, "Statistical Thinking in Sport, Chapman \& Hall CRC," Taylor \& Francis Group, 2008.

[4] Tabor, Statistical Reasoning in Sports. New York: W.H. Freeman and Company, 2013.

[5] P.H. Kvam, J. Sokol, "Teaching Statistics with Sports Examples, INFORMS Transactions on Education," vol. 5(1), pp. 75-87, 2004.

[6] J. Garfield and B. Chance, "Assessment in statistics education, Issuess and Challenges," Mathematics Thinking and Learning, vol. 2, pp. 99125, 2000.

[7] D.J. Rumsey, "Statistical literacy as a goal for introductory statistics courses," Journal of Statistics Education, vol. 10(3), 2002.

[8] A. Zieffler, J. Garfield, S. Alt, D. Dupuis, K. Holleque and B. Chang, "What does research suggest about the teaching and learning of introductory statistics at the college level? A review of the literature," Journal of Statistics Education, vol. 16(2), 2008.

[9] K. Makar and A. Rubin, "A framework for thinking about informal statistical inference," Statistics Education Research Journal, vol. 8(1), 2009.

[10] J. Watson and R. Callingham, "Statistical literacy: A complex hierarchical construct," Statistics Education Research Journal, vol. 2(2), pp. 3-46, 2003.

[11] J.B. Garfield, "The Challenge of Developing Statistical Reasoning," in Journal of Statistics Education, vol. 10(3), 2002. 
cognition and instruction: Twenty-five years of progress. Hillsdale. NJ: Erlbaum, 2001, pp. 347-384

[16] J. Garfield and D.B. Zvi, "Statistical Literacy, Reasoning and Thinking: Goal, Definition and Challlenges," in D. Ben-Zvi \& J.Garfield, Eds. The Challenge of Developing Statistical Literacy, Reasoning, and Thinking. The Netherlands: Kluwer Academic Publishers, USA, 2004.

[17] J. Garfield, Helping Student Develop Statistical Reasoning: Implementing A Statistical Reasoning Learning Environment, 2007, retrieved from: http://www.causeweb.org/workshop/aims/statistical Reasoning Learning Environment.pdf.

[15] M. Lovett, "A Collaborative Convergence on Studying Reasoning Processes: A case study in statistics," In S. M. Carver \& D. Klahr, Eds. 